EDITORIAL

\title{
A note from the editor
}

\section{Lourdes Torres ${ }^{1}$}

Published online: 31 July 2020

(c) Springer Nature Limited 2020

\begin{abstract}
Although the conceptual framework of Latinidades is continually called into question for its gaps and exclusions, I remain committed to its usefulness and its capacity to speak to the range of realities and experiences of Latin American and Caribbean communities residing in the United States. Since its inception, Latinidades has been under construction and ever-evolving as marginalized and excluded subjects make their voices heard and work to revise and reconfigure its meaning. This special issue, "Re-imagining US Colombianidades," focuses our attention on yet another community that has been scantily represented in Latino/a/x studies scholarship. US Colombians are no longer content to be characterized as "the other Latinos," and the editors of this special issue make the case that study of US Colombianidades enhances and productively troubles Latino/a/x studies. This engaging set of essays highlights the rich diversity of US Colombianidades as well as the group's similarities and differences with other Latino/a/x groups. With its innovative cultural studies and social sciences perspectives and interpretive theories, this volume offers a deep dive into issues such as how racial, gender, sexual, and socioeconomic realities shape US Colombian experience; the representation of US Colombians in popular culture; interethnic relations between Colombians and other Latina/o/xs; the political participation of Colombians in US electoral politics; Colombian transnational understandings of identity; and much more. I want to thank the editors of this special issue_Lina Rincón, Johana Londoño, Jennifer Harford Vargas, and María Elena Cepeda-for curating a set of articles that will most certainly inspire Latino/a/x studies scholars to expand our notions of Latinidades and be attentive to the ways in which a focus on US Colombianidades complicates and enriches our field.
\end{abstract}

Lourdes Torres

ltorres@depaul.edu

1 DePaul University, Chicago, IL, USA 
Publisher's Note Springer Nature remains neutral with regard to jurisdictional claims in published maps and institutional affiliations. 